\section{Growth chart: passport to child health care in low-resource settings}

\section{Saurabh R. Shrivastava, Prateek S. Shrivastava, Jegadeesh Ramasamy}

Department of Community Medicine, Shri Sathya Sai Medical College and Research Institute, Kancheepuram, India

\section{Dear Editor}

Under the United Nations Millennium Declaration, 189 countries had adopted the target to achieve Millennium Development Goals (MDG) by the year 2015. ${ }^{1}$ The prevalence of underweight children under-five years of age is an indicator to measure progress towards MDG-1, which aims to halve the proportion of people who suffer from hunger between 1990 and 2015. ${ }^{1}$ Globally, underweight prevalence has declined from $25 \%$ in 1990 to $16 \%$ today. The greatest reductions have been achieved in Central and Eastern Europe, however the situation still remains grim in developing nations and in low-resource settings. ${ }^{2}$ In 2011, an estimated 101 million under-five children were underweight worldwide with the highest contributions from South Asia (59 million) and sub-Saharan Africa (30 million). ${ }^{2}$

The physical growth of infants and underfive children has been recognized as an important parameter to assess health and wellbeing. ${ }^{2,3}$ Multiple interventions - specific (such as use of growth charts, prevention and treatment of acute malnutrition/micronutrient deficiencies, safeguarding the maternal nutritional status, compliance with the infant and young child feeding practices - exclusive breastfeeding for six months followed by complementary feeding, etc.) as well as general (such as promotion of good sanitation practices and access to clean drinking water, promotion of utilization of healthcare services by community involvement, etc.) have been implemented to counter the problem of undernutrition. 4,5

In low-resource settings, supervision and monitoring of growth of under-five children is of immense significance, as it can aid in early detection of acute malnutrition. The growth chart or road-to-health chart is a visual display of the child's physical growth. It is designed primarily for the longitudinal follow-up of a child, so that changes over time can be interpreted. ${ }^{5}$ Growth chart has a unique role in rural and tribal areas where people do not have access to specialists/tertiary care centers/laboratory services readily. ${ }^{3,4}$ Growth charts help in detecting whether a child is receiving adequate nutrition required for the basic physiological need of growth and development., Different types of growth charts have been developed and utilized in varied settings for accurate monitoring of growth of children., ${ }^{3,6,7}$

Apart from growth monitoring, the chart has many potential uses such as a diagnostic tool for identifying high risk children; for planning and designing of policies at the local and central level based on extent of malnutrition prevalent in an area; as an educational aid to illiterate mothers by encouraging her to participate actively in growth of her child; for assisting health worker to decide the type of intervention needed for specific children; and for evaluating the effectiveness of corrective measures / special interventions employed. ${ }^{3,5,6}$

To conclude, growth chart is a scientifically sound, robust tool for monitoring health, well-being and nutritional status of infants and young children in different settings. It is an irreplaceable tool in low-resource settings where if used diligently, can significantly minimize the prevalence of malnutrition and associated complications.

\section{References}

1. WHO. Millennium development goals. Geneva: World Health Organization ed.; 2013. Available from: http://www.who. int/mediacentre/factsheets/fs290/en/

2. Cole TJ. The secular trend in human physical growth: a biological view. Econ Hum Biol 2003;1:161-8.

3. Grummer-Strawn LM, Reinold C, Krebs NF. Use of World Health Organization and CDC growth charts for children aged 0-59 months in the United States. MMWR Morb
Correspondence: Saurabh RamBihariLal Shrivastava, Department of Community Medicine, Shri Sathya Sai Medical College and Research Institute, Thiruporur-Guduvancherry main road, 603108 Kancheepuram, India.

Tel/Fax: +91.988.422.7224

E-mail: drshrishri2008@gmail.com

Key words: growth chart, underweight, lowresource settings, millennium development goals.

Contributions: SS: conception and design, drafting of the article, review of literature, guarantor; PS: drafting the article, review of literature, revising it critically for important intellectual content; JR: general supervision of the research, overall guidance in writing the manuscript.

Conflicts of interests: the authors declare no potential conflict of interests.

Received for publication: 29 June 2013

Accepted for publication: 14 July 2013.

This work is licensed under a Creative Commons Attribution 3.0 License (by-nc 3.0).

(C) Copyright S.R. Shrivastava et al., 2014 Licensee PAGEPress, Italy

Healthcare in Low-resource Settings 2014; 2:1785 doi:10.4081/hls.2014.1785

Mortal Wkly Rep 2010;59:1-13.

4. UNICEF. Improving child nutrition: the achievable imperative for global progress. New York, NY: UNICEF ed.; 2013. Available from: http://www.unicef.org/ publications/ index_68661.html

5. Park K. Preventive medicine in obstetrics, pediatrics and geriatrics. In: Park K, eds. Text book of preventive and social medicine. 21st ed. Jabalpur: Banarsidas Bhanot; 2011. pp 502-5.

6. WHO. WHO child growth standards. Geneva: World Health Organization ed.; 2006. Available from: http://www.who.int/ childgrowth/standards/Technical_report.p df

7. Gulati AK, Kaplan DW, Daniels SR. Clinical tracking of severely obese children: a new growth chart. Pediatrics 2012;130:1136-40. 